\title{
Similarity Solutions for an Internal Heat Generation, Thermal Radiation and Free Convection Unsteady Boundary Layer Flow over a Vertical Plate
}

\author{
M. Y. Ali ${ }^{1, *}$, N. M. R. Zahed ${ }^{1}$, M. N. Uddin ${ }^{1}$, M. J. Uddin ${ }^{1,2}$ \\ ${ }^{1}$ Department of Mathematics, Chittagong University of Engineering \& Technology, Chittagong- \\ 4349, Bangladesh \\ ${ }^{2}$ Department of Electrical \& Electronic Engineering, International Islamic University \\ Chittagong, Chittagong-4318, Bangladesh
}

Received 25 May 2016, accepted in final revised form 15 August 2016

\begin{abstract}
The present paper deals with possible similarity solution of unsteady boundary layer flow over a vertical plate in the presence of internal heat generation, thermal radiation and buoyancy force. Under suitable similarity transformations, the non-linear partial differential equations are transformed into a set of ordinary differential equations. The transformed ordinary differential equations with boundary conditions are then solved numerically by using sixth order Runge-Kutta integration scheme. The effects of the governing parameters on the flow and thermal fields are investigated and shown graphically for various parameters in the velocity and the temperature distributions. The most essential case is discussed in this paper.
\end{abstract}

Keywords: Boundary layer; Heat generation; Thermal radiation; Buoyancy force; Similarity solution; Vertical plate

(C) 2016 JSR Publications. ISSN: 2070-0237 (Print); 2070-0245 (Online). All rights reserved.

doi: http://dx.doi.org/10.3329/jsr.v8i3.27851 J. Sci. Res. 8 (3), 341-353 (2016)

\section{Introduction}

If the motion of the fluid is caused solely due to the difference in density resulting from temperature gradients, without the influence of any external forces like a pump or a fan, the associated heat transfer mechanism is termed as natural or free convection. It is well known that conventional heat transfer fluids including oil, water and ethylene glycol mixture etc. are proof of heat transfer fluids. Since the thermal conductivity of these fluids play an important role on heat transfer coefficient of the medium and the plate. The unsteady free convective problems are important in engineering

\footnotetext{
Corresponding author: ali69cuet@gmail.com
} 
applications. The presence of heat generation on free convection can be seen its significance in the context of space technology and processes involving high temperature. The effects of heat generation may alter the temperature distribution. This may be seen in such applications related to nuclear reactor cores. Sakiadis [1] has considered laminar boundary layer flow over a moving surface. However, Crane [2] discussed boundary layer flow over a stretching sheet. Many researchers [3-9] worked on the problem of moving or stretching plates under different situation. The flow of an incompressible fluid past a moving surface has several engineering applications. The aerodynamics extrusion of plastic sheets, the cooling of a large metallic plate in a cooling bath, the boundary layer along a liquid film in condensation process and a polymer sheet or filament extrudes continuously from a die, are the practical applications of a continuous flat surface. Tsou et al. [10] showed that the Sakiadis flow is physically realizable under laboratory condition and they determined the heat transfer rates for certain values of the Prandtl number. A vast literature of similarity solutions have appeared in the fluid mechanics, heat transfer and mass transfer. Ali et al. [11] investigated the similarity solution of unsteady free convective laminar boundary flow around a vertical heated curvilinear surface. The combined effect of increasing the Prandtl and the Grashof numbers reduces the thermal boundary layer thickness along the plates which is vital in engineering application. Aziz [12] studied similarity solution for laminar thermal boundary layer over a flat plate with a convective surface boundary condition. Moreover Magyari [13] studied the similar problem which was extended by Ishak [14]. Makinde and Olanrewaju [15] investigated the buoyancy effects on thermal boundary layer over a vertical plate with a convective surface boundary condition. An extensive literature is available that deals with flows in the presence of radiation. Raptis et al. [16] studied the effect of thermal radiation on the Magneto hydro dynamic flow of viscous fluid past a semi-infinite stationary plate. Hayat et al. [17] extended the wok of Raptis et al. [16]. The present study is the extended work of Olanrewaju et al. [18] to include the heat generation and the thermal radiation which has application in industry, science and engineering. Similarity solution of unsteady convective boundary layer flow along isothermal vertical plate with porous medium is analyzed by Ali et al. [19]. Parvin et al. [20] analyzed the effects of Reynolds and Prandtl number on mixed convective flow and heat transfer characteristics inside an octagonal vertical channel in presence of a heatgenerating hollow circular cylinder placed at the centre.

In the present research we deal with the study of similarity solution of unsteady boundary layer flow over a vertical plate. The governing partial differential equations are transformed to a set of ordinary differential equations. The transformed equations are leaded to the possible similarity cases. One of the most essential cases is discussed in this paper. Based on the obtained numerical solutions, graphical results for the velocity profiles and the temperature profiles are presented and discussed. We also discussed the effects of various parameters on the skin-friction coefficient and the rate 
of heat transfer at the surface of vertical plate. Finally we discussed our achievements from our present research in conclusion.

\section{Mathematical Formulation}

We assume a two-dimensional unsteady incompressible fluid flow over a vertically heated plate. A stream of cold fluid at temperature $T_{\infty}$ moving over the right surface of the plate with a uniform velocity $U_{\infty}$ while the left surface of the plate is heated by convention from a hot fluid at temperature $T_{f}$ which provides a heat transfer coefficient $h_{f}$. The density variation effect, due to buoyancy force, is taken into account in the momentum equation and the thermal radiation and internal heat generation effects are taking into account in the energy equation. The continuity, momentum, and energy equations describing the flow can be written as

$$
\begin{aligned}
& \frac{\partial u}{\partial x}+\frac{\partial v}{\partial y}=0 \\
& \frac{\partial u}{\partial t}+u \frac{\partial u}{\partial x}+v \frac{\partial u}{\partial y}=v \frac{\partial^{2} u}{\partial y^{2}}+g \beta\left(T-T_{\infty}\right) \\
& \frac{\partial T}{\partial t}+u \frac{\partial T}{\partial x}+v \frac{\partial T}{\partial y}=\alpha \frac{\partial^{2} T}{\partial y^{2}}+Q_{1}\left(T-T_{\infty}\right)-\frac{\alpha}{K} \frac{\partial q_{r}}{\partial y}
\end{aligned}
$$

where $u$ and $v$ are the $x$ (along the plate) and the $y$ (normal to the plate) components of the velocities, respectively, $T$ is the temperature, $v$ is the kinematics viscosity of the fluid, and $\alpha$ is the thermal diffusivity of the fluid and $\beta$ is thermal expansion coefficient, $Q_{1}$ is the heat release per unit mass, $g$ is the gravitational acceleration and $q_{r}$ is the radiative heat flux, respectively. The velocity boundary conditions can be expressed as

$$
\begin{aligned}
& u(x, o, t)=v(x, o, t)=0 \\
& u(x, \infty, t)=U_{\infty}
\end{aligned}
$$

The boundary conditions at the plate surface and far into the cold fluid may be written as

$-K \frac{\partial T}{\partial y}(x, o, t)=h_{f}\left[T_{f}-T(x, 0, t)\right]$

$T(x, \infty, t)=T_{\infty}$

The radiative heat flux $q_{r}$ is described by Rosel and approximation such that

$$
q_{r}=-\frac{4 \sigma}{3 K} \frac{\partial T^{4}}{\partial y}
$$




\section{Similarity Solutions over a Vertical Plate}

where $\sigma$ and $K$ are the Stefan- Boltzmann constant and the mean absorption coefficient, respectively. If the temperature difference between the temperature within the boundary layer and free stream is small, then $T^{4}$ can be expressed as a linear function after using Taylors series about free stream temperature $T_{\infty}$ and neglecting higher-order terms, we get

$T^{4} \approx 4 T_{\infty}^{3} T-3 T_{\infty}^{4}$

Using (8) and (9)

$$
\frac{\partial q_{r}}{\partial y}=-\frac{16 \sigma}{3 K} T_{\infty}^{3} \theta^{\prime \prime}\left(T_{f}-T_{\infty}\right) \frac{U_{\infty}}{v \gamma^{2}}
$$

To reduce the above system of equations into suitable form, we used the method of similarity solutions. Hence the following substitutions are introduced

$$
\begin{aligned}
& x=\xi, t=\tau, \eta=y \sqrt{\frac{U_{\infty}}{v}} \cdot \frac{1}{\gamma(\xi, \tau)}, f^{\prime}(\eta)=\frac{u}{U_{\infty}}, \psi=\sqrt{U_{\infty} v} f(\eta) \gamma(\xi, \tau), \\
& v=\sqrt{U_{\infty} v} \frac{\partial \gamma}{\partial x}\left(\eta f^{\prime}-f\right), \theta=\frac{T-T_{\infty}}{T_{f}-T_{\infty}}
\end{aligned}
$$

where prime denotes differentiation with respect $\eta$ to equation (1-7) reduces to

$$
\begin{aligned}
& f^{\prime \prime \prime}+a_{0} f^{\prime \prime} f+a_{1} \eta f^{\prime \prime}+G r \theta=0 \\
& \left(\operatorname{Pr}^{-1}+R a\right) \theta^{\prime \prime}+\left(a_{1} \eta+a_{0} f\right) \theta^{\prime}+Q \theta=0
\end{aligned}
$$

With the boundary conditions

$$
\begin{aligned}
& f(0)=f^{\prime}(0)=0, \theta(0)=1 \\
& f^{\prime}(\infty)=1, \theta(\infty)=0
\end{aligned}
$$

where

$\gamma \frac{\partial \gamma}{\partial \xi}=a_{0}, \frac{\gamma}{U_{\infty}} \frac{\partial \gamma}{\partial \tau}=a_{1}, \operatorname{Gr}($ Modified Grashof Number $)=\frac{\gamma^{2} g \beta}{U_{\infty}^{2}}\left(T_{f}-T_{\infty}\right)$,

$Q($ Modified heat generation parameter $)=Q_{1} \frac{\gamma^{2}}{U_{\infty}}$,

$R a$ ( Modified Radiation parameter ) $=\frac{16}{3} \frac{\sigma \alpha}{K v} T_{\infty}^{3}$

Similar solution for equations $(12,13)$ exists only when all constants are finite and independent of $\xi$ and $\tau$. We obtain the following relationship

$$
\begin{aligned}
& \frac{\gamma^{2}}{2}=a_{0} \xi+A(\tau) \\
& \frac{d A}{d \tau}=a_{1} U_{\infty}
\end{aligned}
$$


$\frac{d B}{d \xi}=\frac{a_{0}}{U_{\infty}}$

$\frac{\gamma^{2}}{2 U_{\infty}}=a_{1} \tau+B(\xi)$

Taking the product of $d \tau$ and $d \xi$, we obtain

$$
\frac{d A}{d \tau} \cdot \frac{d B}{d \xi}=a_{\mathrm{O}} a_{1}=\text { Constant }
$$

The form of similarity solutions wholly depend on equation (21), which leads to different possible similarity cases. Here we discuss the most important case, where it is taken that $\frac{d A}{d \tau} \neq 0, \frac{d B}{d \xi} \neq 0$.

Using equations (17-20) into (21) and comparing the coefficient of corresponding variables, we obtain

$$
\frac{1}{2} \gamma^{2}=a_{0} \xi+a_{1} U_{\infty}+c_{1}
$$

where $a_{0}, a_{1}$ and $c_{1}$ are constants.

Then equations (12-13) reduce to

$$
f^{\prime \prime \prime}+a_{0} f^{\prime \prime} f+a_{1} \eta f^{\prime \prime}+G r \theta=0
$$

$\left(\operatorname{Pr}^{-1}+R a\right) \theta^{\prime \prime}+\left(a_{1} \eta+a_{0} f\right) \theta^{\prime}+Q \theta=0$

With the boundary conditions

$$
\begin{aligned}
& f(0)=f^{\prime}(0)=0, \theta(0)=1 \\
& f^{\prime}(\infty)=1, \theta(\infty)=0
\end{aligned}
$$

\section{Results and Discussion}

To obtain the solution of the differential equations $(23,24)$ with the boundary conditions $(25,26)$ a numerical procedure based on Runge -Kutta sixth order integration scheme is implemented. The effect of various parameters on the flow and temperature profiles have been determined for different values of Modified Grashof number $G r$, Prandtl number $P r$, heat generation parameter $Q$, thermal radiation parameter $R a$ and the different constants $a_{0}, a_{l}$. The value of $\operatorname{Pr}$ is chosen to 0.72 where it is fixed .The effects of various parameters on the non- dimensional velocity profiles within the boundary layer are depicted in Figs. 1-6. Generally the fluid velocity is zero at the plate surface and increases gradually away from the plate towards the free stream value satisfying boundary condition. From Fig. 1 we see that the Modified $\mathrm{Gr}$ has profuse effects on the boundary layer thickness and it is 
understood that the rate of heat transfer at the plate surface increases with increase in Modified $G r$. Fig. 2 shows the effect of $Q$ on the velocity profiles. The effect of the $P r$ on the velocity profiles is shown in Fig. 3. We observed that the velocity profile decreases with the increase of $\mathrm{Pr}$ which means that the rate of thermal diffusion is slowing. Fig. 4 represents the thermal radiation effect on the velocity profile within the boundary layer where the velocity profile has shown to be increased. It is interesting to note that skin-friction and the rate of heat transfer at the plate surface increases with the increase of $G r$ and $R a$ but decreases with the increase of $P r$. The effect of constants $a_{0}, a_{l}$ on the velocity profiles is depicted by Figs. 5-6, that has shown an increasing behaviour of the fluid velocity within the boundary layer. Generally the fluid temperature is maximum at the plate surface and exponentially decreases to zero far away from the plate satisfying boundary condition. Figs. 7-11 illustrate the behavior of the temperature profiles within the boundary layer. Fig. 8 shows that there is no effect of buoyancy force on the temperature profile and the variation of Modified $\mathrm{Gr}$ on the temperature profile is negligible. The influence of various values of $Q$ on the temperature profiles is presented in Fig. 8. We see that the thermal boundary layer thickness increases with the increases of $Q$ but the temperature profile decreases with the increases of $\mathrm{Pr}$ which is shown in Fig. 9. It is clearly seen from Fig.10 that the effect of thermal radiation on the temperature profile increases with an increase of $R a$ near the plate surface. From Figs. 11-12 we see that for different values of $a_{0}$ and $a_{1}$ the temperature profiles decrease at the plate surface. So it is clearly said that in convective surface boundary condition internal $Q$ and $R a$ enhances the thermal diffusion with the increase of $P_{r}$ and the intensity of the buoyancy force slows down the rate of thermal diffusion within the boundary layer.

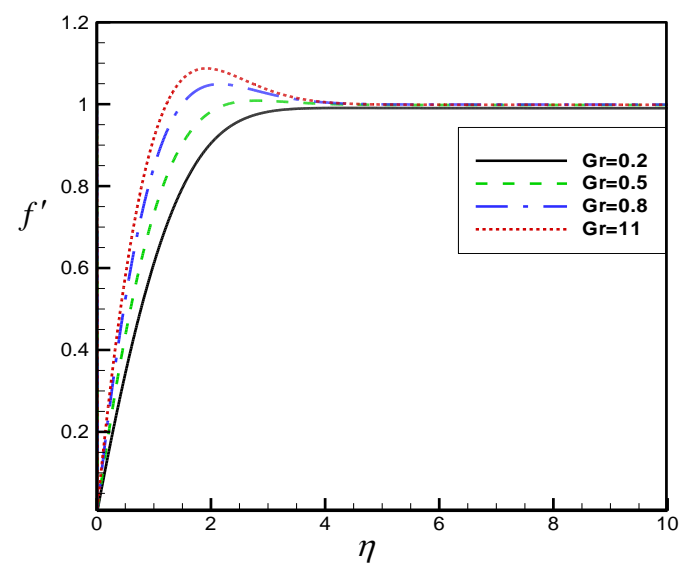

Fig. 1. Velocity profiles for various values of $\mathrm{Gr}$ when $\operatorname{Pr}=0.72, \mathrm{Q}=0.01, \mathrm{Ra}=0.10, \mathrm{a}_{0}=0.20$, $\mathrm{a}_{1}=0.45$. 


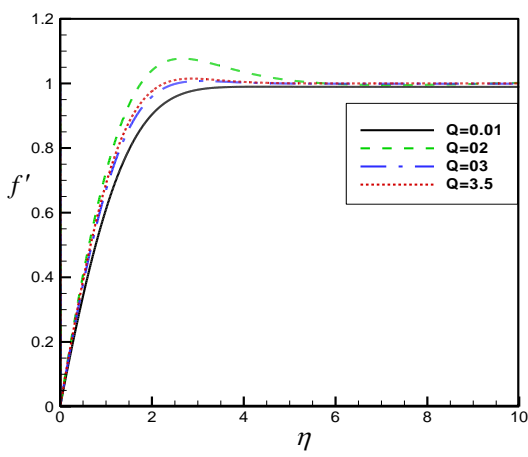

Fig. 2. Velocity profiles for various values of $\mathrm{Q}$ when $\mathrm{Gr}=0.20, \operatorname{Pr}=0.72, \mathrm{Ra}=0.10, \mathrm{a}_{0}=0.20$, $\mathrm{a}_{1}=0.45$.

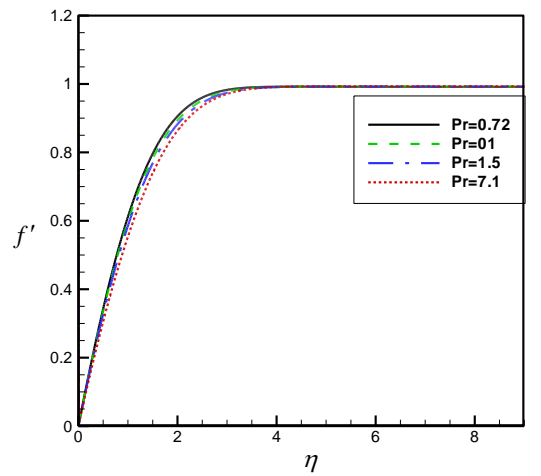

Fig. 3. Velocity profiles for various values of $\operatorname{Pr}$ when $\mathrm{Gr}=0.20, \mathrm{Q}=0.01, \mathrm{Ra}=0.10, \mathrm{a}_{0}=0.20$, $\mathrm{a}_{1}=0.45$.

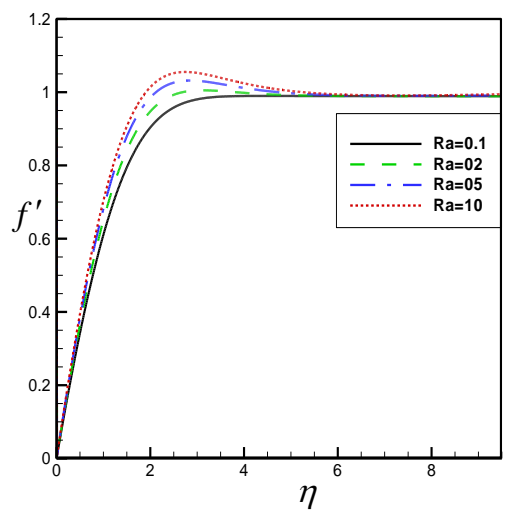

Fig. 4. Velocity profiles for various values of $\mathrm{Ra}$ when $\mathrm{Gr}=0.20, \mathrm{Pr}=0.72, \mathrm{Q}=0.01, \mathrm{a}_{0}=$ $0.20, \mathrm{a}_{1}=0.45$. 


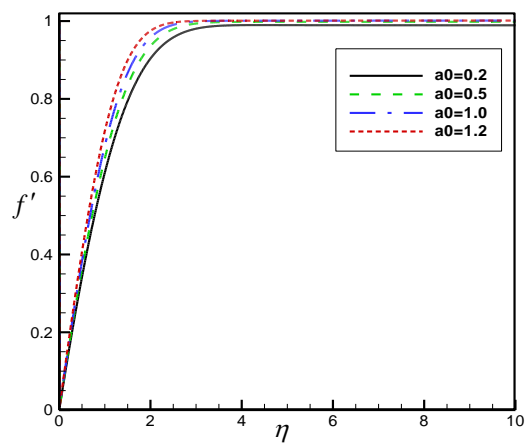

Fig. 5. Velocity profiles for various values of $\mathrm{a}_{0}$ when $\mathrm{Gr}=0.20, \mathrm{Pr}=0.72, \mathrm{Q}=0.01, \mathrm{Ra}=0.10$, $\mathrm{a}_{1}=0.45$.

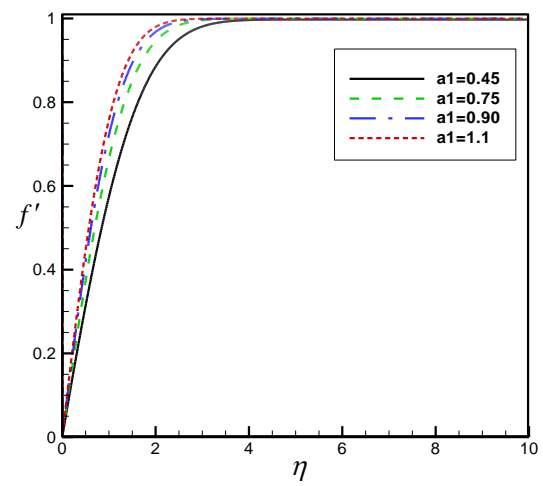

Fig. 6. Velocity profiles for various values of $\mathrm{a}_{1}$ when $\mathrm{Gr}=0.20, \mathrm{Pr}=0.72, \mathrm{Q}=0.01, \mathrm{Ra}=0.10$, $\mathrm{a}_{1}=0.20$.

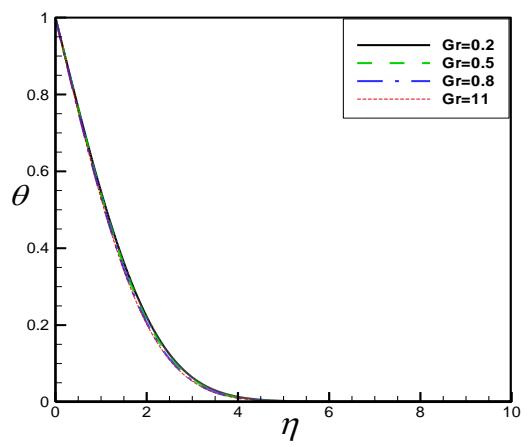

Fig. 7. Temperature profiles for various values of $\mathrm{Gr}$ when $\operatorname{Pr}=0.72, \mathrm{Q}=0.01, \mathrm{Ra}=0.10, \mathrm{a}_{\mathrm{o}}=$ $0.20, \mathrm{a}_{1}=0.45$. 


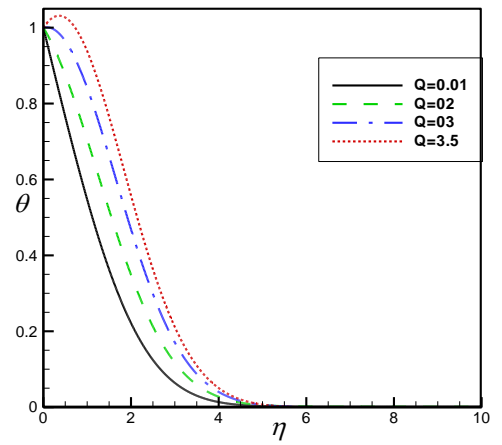

Fig. 8. Temperature profiles for various values of $\mathrm{Q}$ when $\mathrm{Gr}=0.2, \mathrm{Pr}=0.72, \mathrm{Ra}=0.10, \mathrm{a}_{0}=$ $0.20, \mathrm{a}_{1}=0.45$.

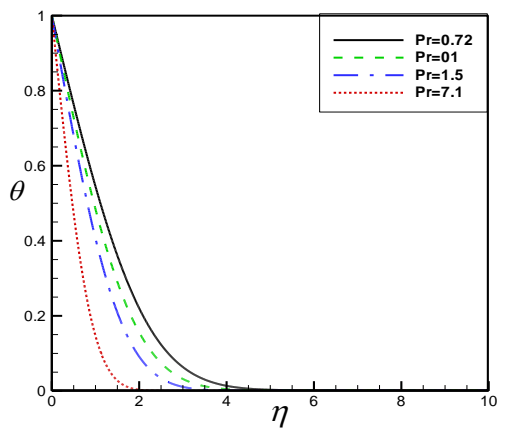

Fig. 9. Temperature profiles for various values of $\operatorname{Pr}$ when $\mathrm{Gr}=0.20, \mathrm{Q}=0.01, \mathrm{Ra}=0.10, \mathrm{a}_{0}=$ $0.20, \mathrm{a}_{1}=0.45$.

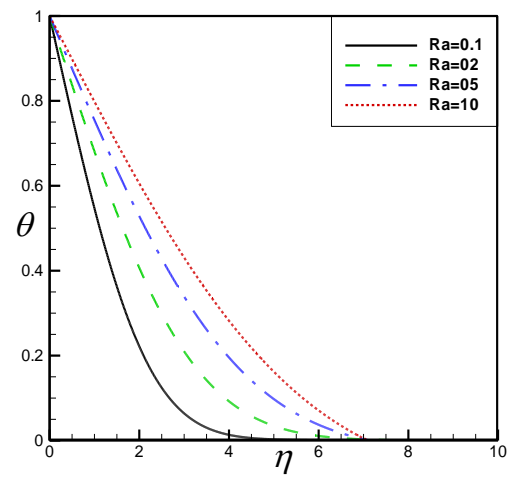

Fig. 10. Temperature profiles for various values of $\mathrm{Ra}$ when $\mathrm{Gr}=0.20, \mathrm{Q}=0.01, \operatorname{Pr}=0.72, \mathrm{a}_{0}=$ $0.20, \mathrm{a}_{1}=0.45$. 


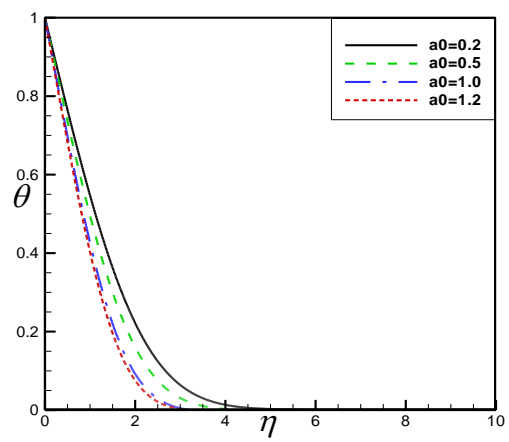

Fig. 11. Temperature profiles for various values of $\mathrm{a}_{0}$ when $\mathrm{Gr}=0.20, \mathrm{Q}=0.01, \operatorname{Pr}=0.72, \mathrm{Ra}=$ $0.10, \mathrm{a}_{1}=0.45$.

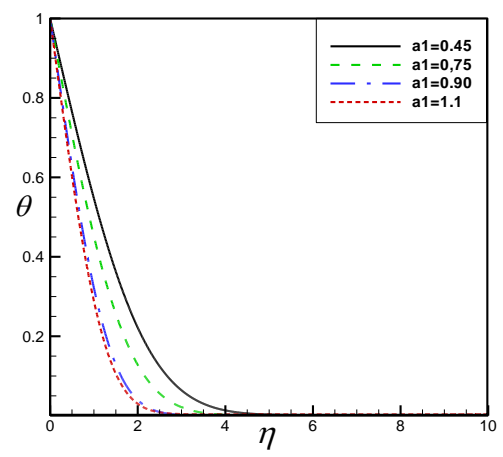

Fig. 12. Temperature profiles for various values of $\mathrm{a}_{1}$ when $\mathrm{Gr}=0.20, \mathrm{Q}=0.01, \operatorname{Pr}=0.72, \mathrm{Ra}=$ $0.10, \mathrm{a}_{0}=0.20$.

Given Tables 1-6 illustrate the values of the skin-friction coefficient and the local Nusselt number in terms of $f^{\prime \prime}(0)$ and $-\theta^{\prime}(0)$ respectively. From the Tables 1, 2 and 4 it is understood that the Skin-friction co-efficient and the rate of heat transfer at the plate surface increases with an increase of Modified $G r$, convective surface internal $Q$ and $R a$ where Nusselt number decreases for $G r$ and $R a$ but increases for $Q$. However, an increase of the fluid $\mathrm{Pr}$ in Table 3 decreases both the skin-friction and Nusselt number. In Table 5, we see that the skin-friction and Nusselt number increases with the increase of constant $a_{0}$. For an increase of unsteadiness parameters $a_{l}$ in Table 6 , the Skin-friction co-efficient increases while the Nusselt number decreases.

Table 1. $f^{\prime \prime}(0)$ and $-\theta^{\prime}(0)$ for different values of Gr.

\begin{tabular}{lll}
\hline$G r$ & $f^{\prime \prime}(0)$ & $-\theta^{\prime}(0)$ \\
\hline 0.20 & 0.699510 & 0.476854 \\
0.50 & 1.002710 & 0.487101 \\
0.80 & 1.194096 & 0.493229 \\
11 & 1.202118 & 0.493238 \\
\hline
\end{tabular}


Table 2. $f^{\prime \prime}(0)$ and $-\theta^{\prime}(0)$ for different values of $\mathrm{Q}$.

\begin{tabular}{lll}
\hline$Q$ & $f^{\prime \prime}(0)$ & $-\theta^{\prime}(0)$ \\
\hline 0.01 & 0.699510 & 0.476854 \\
02 & 0.787247 & 0.190450 \\
03 & 0.820777 & -0.025153 \\
3.5 & 0.847745 & -0.173828 \\
\hline
\end{tabular}

Table 3. $f^{\prime \prime}(0)$ and $-\theta^{\prime}(0)$ for different values of $\operatorname{Pr}$.

\begin{tabular}{lll}
\hline$P r$ & $f^{\prime \prime}(0)$ & $-\theta^{\prime}(0)$ \\
\hline 0.72 & 0.729510 & 0.476854 \\
01 & 0.727943 & 0.553109 \\
1.5 & 0.705898 & 0.655923 \\
7.1 & 0.661944 & 1.138544 \\
\hline
\end{tabular}

Table 4. $f^{\prime \prime}(0)$ and - $\theta^{\prime}(0)$ for different values of Ra.

\begin{tabular}{lll}
\hline$R a$ & $f^{\prime \prime}(0)$ & $-\theta^{\prime}(0)$ \\
\hline 0.10 & 0.699510 & 0.476854 \\
02 & 0.792543 & 0.326473 \\
05 & 0.828729 & 0.248440 \\
10 & 0.854400 & 0.203246 \\
\hline
\end{tabular}

Table 5. $f^{\prime \prime}(0)$ and $-\theta^{\prime}(0)$ for different values of $\mathrm{a}_{0}$.

\begin{tabular}{lll}
\hline$a_{0}$ & $f^{\prime \prime}(0)$ & $-\theta^{\prime}(0)$ \\
\hline 0.20 & 0.699510 & 0.476854 \\
0.5 & 0.766682 & 0.535291 \\
01 & 0.853159 & 0.619320 \\
1.2 & 0.879068 & 0.643724 \\
\hline
\end{tabular}

Table 6. $f^{\prime \prime}(0)$ and $-\theta^{\prime}(0)$ for different values of $\mathrm{a}_{1}$.

\begin{tabular}{lll}
\hline$a_{1}$ & $f^{\prime \prime}(0)$ & $-\theta^{\prime}(0)$ \\
\hline 0.45 & 0.699510 & 0.476854 \\
0.75 & 0.853477 & 0.597852 \\
0.90 & 0.912572 & 0.649235 \\
1.1 & 0.978666 & 0.711843 \\
\hline
\end{tabular}

\section{Conclusion}

For the two dimensional unsteady boundary layer flow over a vertical plate with the similarity case, $\frac{d A}{d \tau} \neq 0, \frac{d B}{d \xi} \neq 0$, we can draw the following conclusion studied in this paper : 
(a) With an increase of the Grashof number $G r$ the velocity profiles increases but the increase of $\mathrm{Gr}$ the temperature profiles decreases. It also seen that the values of skinfriction coefficient and heat transfer increases but Nusselt number decreases.

(b) With an increase of Prandtl number $\operatorname{Pr}$ both the velocity and temperature profiles decreases. Also both the co-efficient of skin-friction and heat transfer decreases with the increase of the Prandtl number.

(c) Increase of thermal radiation both the velocity and the temperature profiles increases where the Skin-friction co-efficient increases but Nusselt number decreases.

(d) The velocity and temperature profiles increases with the increase of heat generation parameters where both Skin-friction co-efficient and Nusselt number also increases.

(e) Skin-friction co-efficient increases but Nusselt number decreases for the increase of unsteadiness parameters and the arbitrary constant.

Further investigation is necessary to deal with the other possible similarity cases in order to draw the overall remarks conclusively.

\section{Acknowledgment}

The authors are highly thankful to the authority of Chittagong University of Engineering \& Technology (CUET) for providing technical supports during this research work at Simulation Lab, Department of Mathematics, CUET, Chittagong4349, Bangladesh.

\section{References}

1. B. C. Sakiadis, AIChE J. 7, 26 (1961). http://dx.doi.org/10.1002/aic.690070108

2. I. J. Crane and Z. Angew, Math. Phys. 21(56), 1 (1970).

3. P. S. Gupta and A. S. Gupta, Can. J. Chem. Eng. 55, 744 (1977). http://dx.doi.org/10.1002/cjce.5450550619

4. P. Carragher and I. J. Crane, Z. Angew. Math. Mech. 62, 564 (1982). http://dx.doi.org/10.1002/zamm.19820621009

5. J. E. Danberg and K. S. Fansler, Quart. Appl. Math. 34, 305 (1976).

6. A. Chakrabarti and A. S. Gupta, Quart. Appl. Math. 37, 73 (1979).

7. K. Vajravelu, Acta Mech. 64, 179 (1986). http://dx.doi.org/10.1007/BF01450393

8. B. K. Dutta, Acta Mech. 78, 255 (1986). http://dx.doi.org/10.1007/BF01179221

9. S. L. Lee and J. S. Tsai, Int. J. Heat Mass Transfer 33, 457 (1990). http://dx.doi.org/10.1016/0017-9310(90)90181-S

10. F. K. Tsou, E. M. Sparrow, and R. J. Glodstein, Int. J. Heat Mass Transfer 10, 219 (1967). http://dx.doi.org/10.1016/0017-9310(67)90100-7

11. M. Y. Ali and M. M .T. Hossain, Int. J. Appl. Math and Stat. 30(6), 1 (2012)

12. A. Aziz, Commun. Nonlinear Sci. Numer. Simul. 14, 1064 (2009). http://dx.doi.org/10.1016/j.cnsns.2008.05.003

13. E. Magyari, Nonlinear Sci. Numer. Simul. 16, 599 (2011). http://dx.doi.org/10.1016/j.cnsns.2010.03.020

14. A. Ishak, Appl. Math. Comput. 217, 837 (2010). http://dx.doi.org/10.1016/j.amc.2010.06.026

15. O. D. Makinde and P. O. Olanrewaju, ASME J. Fluid Eng. 132, ID 044502 (2010).

16. A. Raptis, C. Perdikis, and H. S. Takhar, Appl. Math.Comput. 153, 645 (2004). http://dx.doi.org/10.1016/S0096-3003(03)00657-X 
17. T. Hayat, Z. Abbas, M. Sajid, and S. Asghar, Int. J. Heat Mass Transfer 50, 931 (2007). http://dx.doi.org/10.1016/j.ijheatmasstransfer.2006.08.014

18. P. O. Olanrewaju, J. A. Gbadeyan, and T, Hayat, Can. J. Chem. Eng. 90, 1289 (2012).

19. M. Y. Ali, M. N. Uddin, M. J. Uddin, and N. M. R. Zahed, Open J. Fluid Dynamics 5, 391 (2015). http://dx.doi.org/10.4236/ojfd.2015.5403.

20. S. Parvin and R. Nasrin, J. Sci. Res. 4(2), 337 (2012).

http://dx.doi.org/10.3329/jsr.v4i2.8142 